\title{
An atypical case of peripheral arterial thrombosis complicated with thromboembolism
}

\author{
Madalina Maria Budur ${ }^{*, 1}$, Gheorghe losub ${ }^{2}$, Ionut Munteanu ${ }^{3}$ \\ 1"Carol Davila" University of Medicine and Pharmacy, Bucharest, Romania, ${ }^{2}$ Department of \\ Orthopaedic and Traumatology, Emergency University Hospital Bucharest, Romania, ${ }^{3}$ Department of \\ Vascular Surgery, Sanador Hospital Bucharest, Romania
}

\begin{abstract}
We report the case of a 47 year-old patient diagnosed with peripheral occlusive arterial disease stage IV. The disease was diagnosed after an 8 months evolution of the symptoms, on a foreground including susceptibility factors such as smoking, high blood cholesterol, hypertension and dehydrating environment. The difficulty in diagnosing was due to the patient's lack of cooperation and to the fact that he lives in a desert area, not being able to reach medical care immediately. Differential diagnosis with peripheral arterial disease in diabetes, inflammatory arterial disease, collagen diseases and Buerger's disease is required. The particularities of the case are the presence of extensive atheromatous lesions at young age and dry, dehydrating environment, favoring and worsening the condition. As for patient's evolution, despite following well-conducted antithrombotic treatment, after 3 weeks interval, postoperative arterial thrombosis occurred on controlateral limb.
\end{abstract}

Keywords: occlusive peripheral arterial disease, acute limb ischemia, atherosclerosis, iliofemoral bypass

\section{Introduction}

Peripheral vascular disease represents an occlusive or inflammatory disease that develops within the peripheral arteries, favored by a number of risk factors [1]. Peripheral arterial disease (PAD) is associated with a high risk of vascular events whether PAD is symptomatic or asymptomatic. PAD is considered an equivalent of coronary heart disease because of the high associated risk [2]. PAD is also associated with complications, including infection or tissue necrosis, which may require amputation. Risk factors comprise: cigarette smoking, diabetes, high blood pressure, obesity, high blood

Received: May 2015; Accepted after review: June 2015; Published: June 2015.

${ }^{*}$ Corresponding author: Madalina Maria Budur, University of Medicine and Pharmacy "Carol Davila" Bucharest, Romania.

Email: madalina.budur@yahoo.com cholesterol, age over 50 [3, 4]. The mechanisms of PAD include atherosclerosis in $90 \%$ of cases, atherosclerotic plaques occurring most frequently at the arterial branching where the blood flow is turbulent.

The physical examination reveals absent pulse and decreased temperature of the limb distal to the occlusion [1].

\section{Case report}

A 47 year-old man known with untreated hypercholesterolemia, hypertension and smoking addiction is difficultly diagnosed with occlusive peripheral arterial disease stage IV, eight months after the symptoms arose, symptoms consisting of intermittent claudication with a walking perimeter about 150 meters. The patient reported pain in the first left toe and the physical examination shows cyanosis, low temperature (Figure 1), 
atrophy of the limb, loss of sensitivity and severe joint pain $[3,5]$.

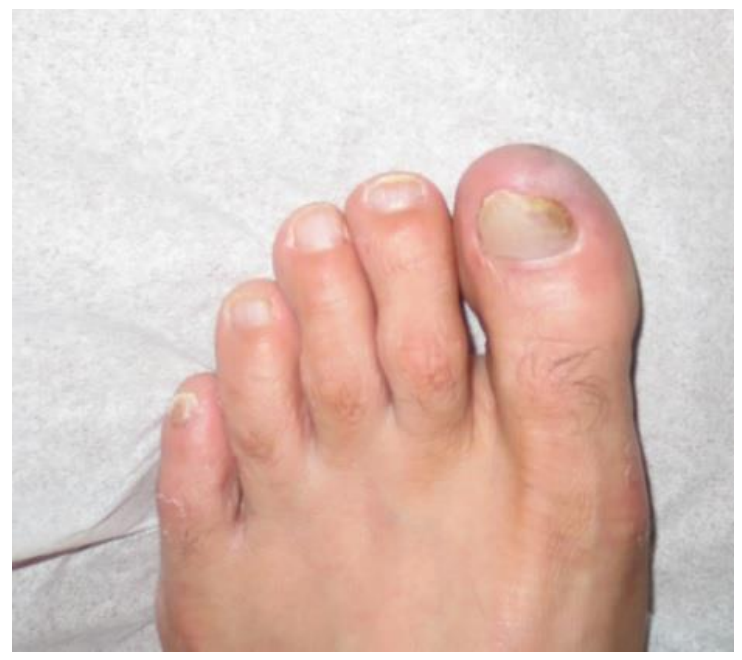

Fig. 1. The cyanosis of the toe

The patient refused to cooperate and took self-medication, consisting of painkillers. After 3 months of evolution, the first symptom which alarmed the patient was the appearance of an ulcerated lesion (Figure 2) of the distal left phalanx of the first toe, as a complication of ischemia, determining the patient to readdress to the physician.

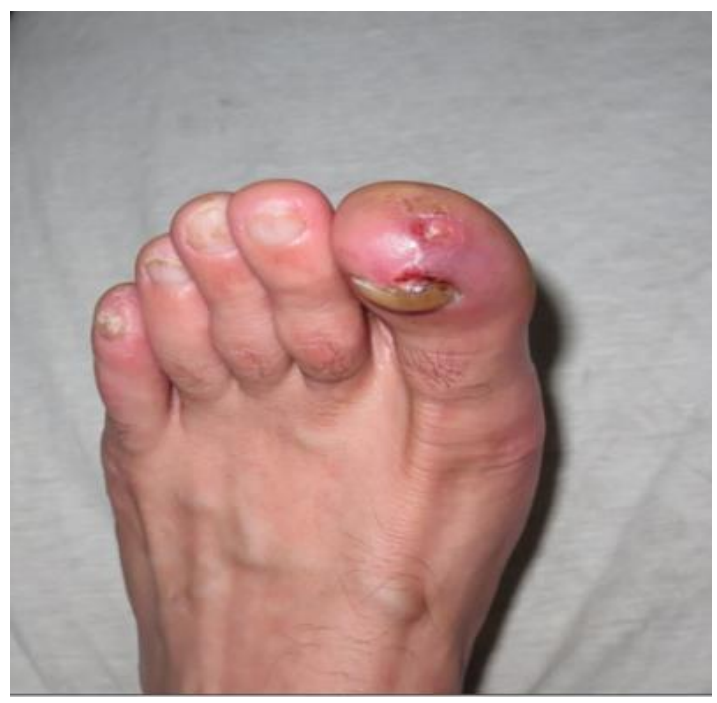

Fig. 2. Aspect of the ulceration

Samples were taken from the lesion of the distal left phalanx of the first toe and sent to the microbiology laboratory for culture, and sensitivity drug testing. The results revealed the presence of Staphylococcus aureus spp and rare colonies of Candida spp. (Table 1). The antimicrobial therapy, including an antibiotic (Ofloxacin) and an antifungal drug (Fluconazole), was initiated. Initially, a short improvement was noticed, but after discharge, a relapse was registered, due to the lack of patient's adherence to the treatment. After 3 months, the patient returned to his homeland to receive medical care.

Table 1. Culture wound of the distal left phalanx of the first toe

\begin{tabular}{|c|c|}
\hline Culture wound & $\begin{array}{c}\text { The absence of overt pathogenic } \\
\text { aerobic bacterial flora and } \\
\text { Staphylococcus aureus spp. } \\
\text { Presence of Candida albicans spp } \\
\text { Itraconazol, Fluconazol, Nystatin, } \\
\text { Sensitive }\end{array}$ \\
\hline $\begin{array}{c}\text { Ketoconazol, Flucytosinc, Voriconazol, } \\
\text { Amphotericin B }\end{array}$ \\
\hline Resistant & Econazol, Miconazol, Clotrimazol \\
\hline
\end{tabular}

At the further admission in our department, blood serological investigations and a sample from the ulceration were taken (Figure 3). The results showed the absence of Staphylococcus aureus spp and the presence of Candida albicans spp.

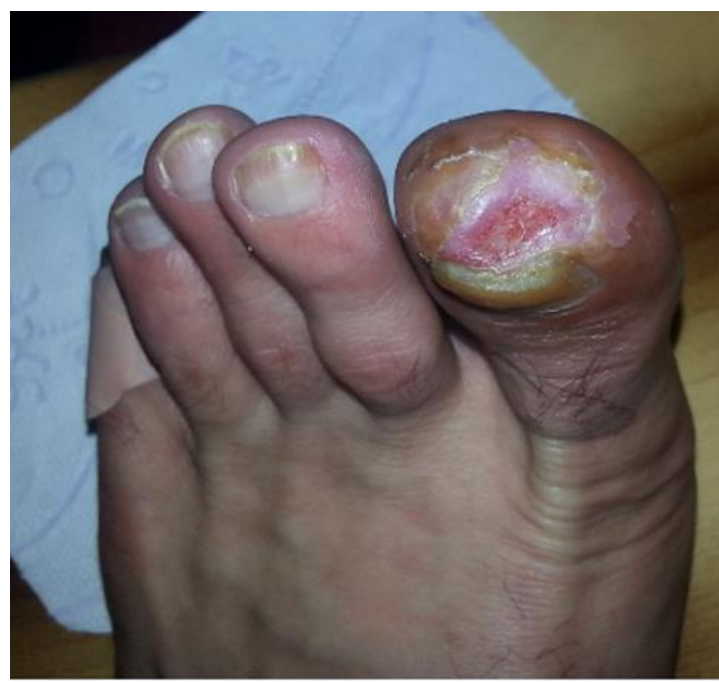

Fig. 3. The aspect of the ulceration 3 months later. The loss of tissue is important

The blood test results revealed high levels of: calcium, glucose, cholesterol, LDL, triglycerides, lipids, hematocrit and hemoglobin (Table 2). 
Table 2. Laboratory results

\begin{tabular}{|l|c|c|}
\hline & Results & Reference values \\
\hline $\begin{array}{l}\text { Total serum } \\
\text { calcium }\end{array}$ & 10.71 & $8.6-10.3 \mathrm{mg} / \mathrm{dl}$ \\
\hline $\begin{array}{l}\text { Total } \\
\text { cholesterol }\end{array}$ & 301.8 & $120-240 \mathrm{mg} / \mathrm{dl}$ \\
\hline $\begin{array}{l}\text { Blood } \\
\text { Glucose }\end{array}$ & 128.2 & $70-110 \mathrm{mg} / \mathrm{dl}$ \\
\hline $\begin{array}{l}\text { LDL } \\
\text { cholesterol }\end{array}$ & 190.7 & $1-130 \mathrm{mg} / \mathrm{dl}$ \\
\hline $\begin{array}{l}\text { Total Fats } \\
\text { Triglyceride }\end{array}$ & 969.45 & $400-800 \mathrm{mg} / \mathrm{dl}$ \\
\hline serum & 200.4 & $30-200 \mathrm{mg} / \mathrm{dl}$ \\
\hline
\end{tabular}

The patient was transferred to the cardiology department with the suspicion of diabetic arterial disease in the context of altered laboratory results. Oscillometry was performed, showing the absence of the femoral pulse in the left leg and also no pulse in the posterior tibial artery (Figure 4).

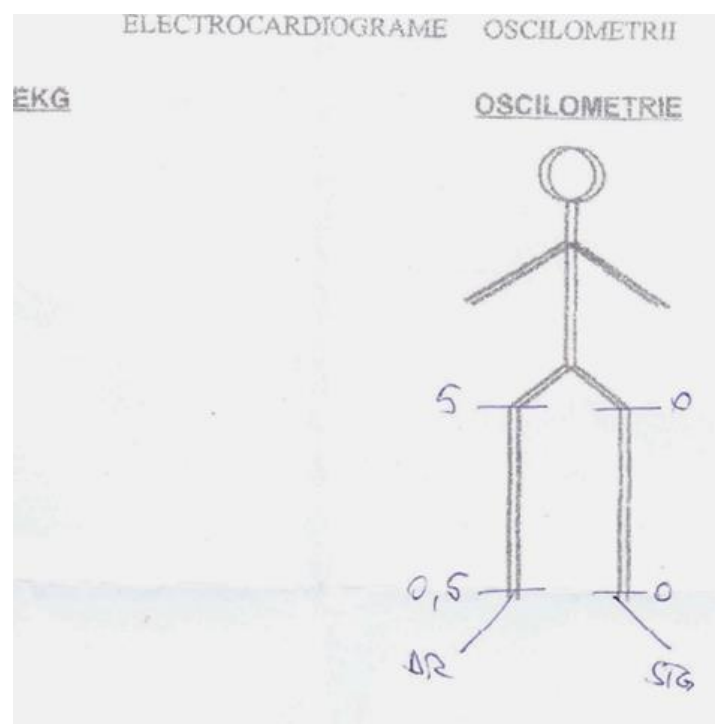

Fig. 4. The oscillometry shows the absence of left femoral pulse and on the posterior tibial artery

The cardiological consult included heart function evaluation by EKG, transthoracic ultrasound, and Doppler ultrasound.

The transthoracic ultrasound described a normal left ventricle with no valvulopathy and normal pericardium. The Doppler ultrasound indicated a complete obstruction and revealed the diagnosis of occlusive peripheral arterial disease stage 4 because of the patient history of smoking, dyslipidemia, high blood pressure, dehydration. The therapy with antiplatelet drugs (Trombex $75 \mathrm{mg}$, Aspirin 100mg), anticoagulants (Vessel Due), vasodilator (Pentoxifylline $400 \mathrm{mg}$ ) and medication for hyperlipidemia (Crestor $20 \mathrm{mg}$ ) was initiated.

The next step was the arteriography (Figure 5), using brachial approach and revealing the occlusion of the left iliac artery, leading to the indication for surgery.

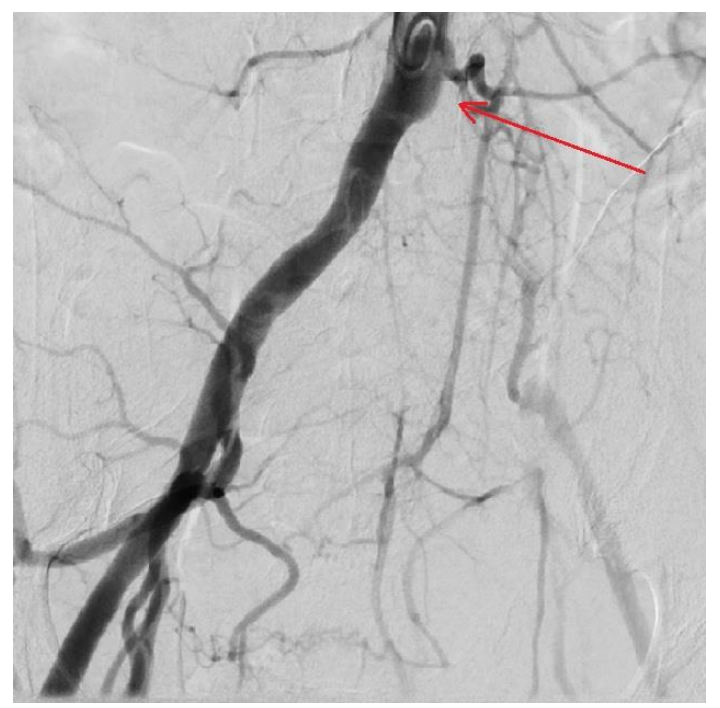

Fig. 5. Arteriography indicating the thrombus location. The left iliac artery does not receive blood in compared to the right iliac artery

The evolution was favorable, with distal pulse present bilaterally, normal temperature of the tegument and healing of the ulceration.

\section{Discussions}

Peripheral arterial thrombosis is usually characterized by decreased peripheral pulse (ankle brachial index $<1.0 ;<0.5$ with severe ischemia), blanching of affected limb with elevation, dependent rubor (redness); ischemic ulcers or gangrene of toes may be present [1]. The common differential diagnosis of peripheral arterial thrombosis includes Buerger's disease, which may be suspected in our case by the patient's age (usually affecting men in their 50s) arteriosclerotic degenerative changes occurring with aging [6]. Other differential diagnosis includes diabetes, 
collagen diseases, inflammatory arterial disease and peripheral occlusive arterial disease.

For the present case, the iliofemoral bypass was performed with Dacron Ag 8 graft. The studies show that the iliofemoral bypass is used in cases of isolated iliac or proximal common femoral artery occlusive disease, provided that the aorta and the proximal ipsilateral common iliac artery are free of severe occlusive disease [7].

In our case, twenty four hours after the surgery, acute limb ischemia occurred in the right limb. Thrombectomy at popliteal artery was performed using Fogarty catheter to save the tissue and forestalling gangrene from occurring in 4-6 hours and compromising the tissue. The origin of the clot that migrated after the 24 hour postoperatively was uncertain, taking into account that the patient was under antithrombotic medication [5]. Even if the patient is young he was diagnosed with PAD instead of Buerger's disease, which was more likely for this case because of the smoking history, the age and the lesion. Apparently, the patient had extensive atheromatous lesions, located proximally from the thrombosis (the branching of the iliac arteries). During the process of diagnosing and treatment, complications overlapped, including infection and postoperative acute limb ischemia [6, 8].

Occlusive peripheral arterial disease is usually common among old age group (due to

\section{References}

1. Longo DL, Fauci AS, Kasper DL, Hauser SL, Jameson JL, Loscazlo J. Harrison's Manual of Medicine. $18^{\text {th }}$ Edition. New York: Mc Graw Hil Medical 2013; 3346-3352.

2. Stella $M$, Daskalopoulou $S$, Marios $E$, et al. Europen Manual of medicine-Lipids and Peripheral arterial disease. Berlin: Springer Heidelberg 2007; 35-38.

3. Wold heart federation. Cardiovascular diseaserisk factors: [http://www.world-heartfederation.org/fileadmin/user_upload/document s/Fact_sheets/2012/PressBackgrounderApril20 12RiskFactors.pdf available at 05.15.2015].

4. Angelescu N. Tratat de patologie chirurgicala, arteriopatii cornice periferice obstructive. Bucuresti: Editura Medicala, 2013; 2213-2215. atherosclerosis) and affects 15 to $20 \%$ of people older than 70 [8].

The fact that this case was difficult to diagnose is particularly because the patient's working conditions abroad, in a desert area, representing a risk factor for dehydration and increased blood viscosity. Furthermore, the patient was under the common age group, among which this pathology is prevalent and his evolution included several complications.

The revascularization is essential to reestablish the blood flow and must be associated with postoperative medication and diet [8]. For the discussed case, bypass grafting was preferred because it offered the most durable, reliable and expeditious reconstruction.

\section{Conclusions}

In conclusion, this case is particular due to patient's age (younger than the common age group for this pathology) and to the difficulty in diagnosis because of the patient's lack of cooperation and the impossibility to promptly access medical care.

Another feature of this case was the context favorable for dehydration, representing a worsening factor of the pathology's evolution. Moreover the case was complicated postoperatively with acute limb ischemia, requiring a new intervention to rescue the limb.

5. Cuong L, Ripal T, Vatakencherry G, Katzen BT. Iliac artery revascularization. Interventional Cardiology 2010; 2(6): 851-859.

6. Rutherford RB. Vascular Surgery Buerger's. Third Edition. Portland - Oregon: W B Saunders Company, 1989; 207-211.

7. Mueller DK, Vincent LR. Iliofemoral Bypass. MedscapeJ June 2013: [http://emedicine.medscape.com/article/183029 8-overview available at 05.15.2015].

8. http://www.merckmanuals.com/professional/car diovascular-disorders/peripheral-arterialdisorders/peripheral-arterial-disease_available at 05.15.2015]. 